\title{
Surgical Site Infection and Incidence of Mrsa Using Phenotypic and Genotypic Methods from Tertiary Care Hospital
}

\author{
Karthika Priya ${ }^{*}$.S, Somasundar.V.M, Rajesh.J.G, Padma Priya, \\ Muthulakshmi , Kamal Raj. M \\ Department of Microbiologyy, Meenakshi Medical College \& Research Institute, Kanchipuram, Chennai, India
}

\begin{abstract}
Postoperative Surgical Site Infection (SSI) remains as the major reason for mortality and morbidity. The study was performed with the aim to find out the incidence of SSI and MRSA, in the patients who underwent clean and clean- contaminated surgeries in the Dept. of Obstetrics and Gynaecology at Meenakshi Medical College Hospital and Research Institute, Enathur, Kanchipuram. A total 62 cases that developed signs and symptoms of SSI were taken for study out of 1240 cases operated from Obstetrics and Gynaecology ward with incidence of SSIs being 5\%. Out of 62 cases the predominant isolate was Staphylococcus aureus 35(56.45\%). Among various surgeries reported in our study highest incidence of SSIs in Lower Segment Caesarean Section (LSCS) 39(3.1\%) and lowest incidence of SSIs was observed in salphingo-oophrectomy 1(0.1\%) respectively. The incidence of SSIs increased in case of emergency surgeries 22(19.6\%) with that of elective surgeries $40(3.5 \%)$ with significant p value $<0.0001$. Out of 35 Staphylococcus aureus isolates $7(20 \%)$ isolates were resistant to cefoxitin by disc diffusion method and positive for mec A gene using PCR. A working knowledge of the prevalent organism, risk factors and resistance profile will help the infection control practitioner and surgeon to treat the infection effectively at the earliest, reduce the incidence of SSI and also prevents spread of multidrug resistant strains like MRSA which increases mortality and morbidity in patients undergoing surgery.
\end{abstract}

\section{Introduction}

Surgical Site Infections (SSIs) occurs within 30 days after surgical procedure, but in case of use of implants the duration extends to one year from the day of surgery. ${ }^{(2)}$ SSI remains as the major reason for morbidity and mortality in patients undergoing surgery, even with the advances in the surgical techniques, better understanding of the pathogenesis of wound infections \& wound healing. ${ }^{(1)}$ The overall incidence of wound sepsis in India is from $10 \% 33 \%$. However, the incidence of wound complications in the obstetric population varies with rates ranging from $2.8 \%$ to $26.6 \%$. $^{(1)}$

SSI is defined as the infection occurring within 30 days of surgery or within a year in the case of implants left in the place of surgery, according to Centre for Disease Control and prevention (CDC). SSI can be classified into three types,

1. Superficial surgical site infection- which invoves only skin \& subcutaneous tissues.

2. Deep incisional surgical site infection- involves deep soft tissues i.e. fascia \& muscle layer of the incision.

3. Organ-space surgical site infection- infection involves any part of the anatomy other than the skin, incision, fascia \& muscle layer that is opened or manipulated during the surgery. ${ }^{(2,14,15)}$

SSI accounts for $2-20 \%$ of nosocomial infections, it is one of the most common complication associated with surgery. ${ }^{(1,14,15)}$ The factors influencing SSI are pre-existing illness, length of operation, woumd class, extremes of ages, malignancy, metabolic diseases, malnutrition, immunosuppression, remote site infection, cigarette smoking, emergency procedures, surgical techniques, skin preparation techniques, timing \& method of wound closure, antibiotic prophylaxis and prolonged preoperative / postoperative hospitalization. ${ }^{(3,4)}$ Based on the surgical site, study population and antimicrobial use within the hospital determines the organism isolated from the SSI, it vary with each hospital. ${ }^{(3,4)}$

Based on the degree of microbial contamination, surgical wounds are classified in to four types,

1. Clean wound

2. Clean contaminated wound

3. Contaminated wound

4. Dirty wound

Among all the four wound class, Staphylococcus aureus is the most predominant isolate followed by Pseudomonas aeruginosa, Proteus vulgaris, Escherichia coli, Klebsiella species, and Enterococcus species respectively. ${ }^{(3,4)}$ The management of postoperative infection is further complicated by multidrug resistant organism like MRSA. A working knowledge on factors causing SSIs, pathogenesis, etiology, risk factors and 
Surgical Site Infection And Incidence Of Mrsa Using Phenotypic And Genotypic Methods....

resistance pattern will help in rationalizing, the use of appropriate antibiotics with proper timing $\&$ dosage for surgical prophylaxis. ${ }^{(14,15,26)}$

\section{Materials And Methods}

The prospective study was conducted at Department of Microbiology, MMCH \& RI, Ethanur, Kanchipuram from patients who developed signs and symptoms of surgical site infection in the Obstetrics and Gynaecology Department were obtained. Institutional ethical clearance was obtained. After obtaining consent from the patients, pus swabs were collected from depth of the wound or aspirate collected from the wound. $(6,16,26)$

Study period: March -2014 to May -2015

Inclusion criteria:- Clean and clean contaminated surgeries from Obstetrics and Gynaecology ward Exclusion criteria:- Contaminated and dirty wounds

Patient not coming for follow up till 30 days after surgery. The specific identification of bacterial pathogen was done based on microscopic morphology, staining characteristics, motility, cultural and biochemical properties using standard laboratory techniques.

\section{Detection of Methicillin Resistance In Staphylococcus Aureus:}

1. Oxacilin screen agar: Mueller-Hinton agar (MHA) plates containing $4 \% \mathrm{NaCl}$ and $6 \mu \mathrm{g} / \mathrm{ml}$ of oxacillin were prepared. Plates were spot inoculated with $10 \mu \mathrm{L}$ of $0.5 \mathrm{McFarland}$ suspension of the isolate and incubated at $35 \square \mathrm{C}$ for $24 \mathrm{hrs}$. MHA plates were observed carefully in transmitted light for any growth, growth after $24 \mathrm{hrs}$ was considered oxacillin resistant. ${ }^{(11)}$

2. Cefoxitin disc diffusion test: All the isolates suspension was prepared against 0.5 MacFarland turbidity standards, lawn culture was made and cefoxitin disc 30 $\mu \mathrm{g}$ was kept on MHA plate. Plates were incubated for 18 hours at 370C. Based on, zone diameter reported as oxacillin sensitive or resistant.

3. Minimum inhibitory concentration (MIC): The antibiotic sensitivity testing was done to find the resistance among the isolates using Kirby-Bauer disc diffusion method. MIC was done only for cefoxitin to confirm whether it is MRSA strain. MIC was done by microbroth dilution method, according to CLSI guidelines. The starting dilution was $2048 \mu \mathrm{g} / \mathrm{ml}$ up to $2 \mu \mathrm{g} / \mathrm{ml}$ concentration. The stock \& working solution of antibiotic was prepared and microbroth dilution was done in microtitre plate by double fold serial dilution was done. Overnight culture was matched to 0.5 Mac farland standards and used as inoculum. After dilution the plates were incubated at $370 \mathrm{C}$ for 18-24 hours. After incubation the plates were taken for minimum bactericidal concentration (MBC) to determine the bactericidal concentration. The MIC \& MBC are determined. (CLSI GUIDELINES 2013)

4. Detection of mec a genes by pcr: ${ }^{(24)}$ Detection of MRSA genes (mecA) were performed as described Anand et al 2009. Bacterial DNA Extraction Kit was used for bacterial DNA extraction according to manufacturer's protocol (Xcleris Ltd).Briefly DNA was extracted from overnight broth culture and DNA was trapped in Column following the manufacturer's protocol. Eluted DNA was stored at $-20^{\circ} \mathrm{C}$ for further use. PCR amplification was done with specific gene primers and checked for the presence of mecA gene.

Primer sequence used to detect mec A gene in our study

\begin{tabular}{|l|l|l|}
\hline PRIMER & PRIMER SEQUENCE & $\begin{array}{l}\text { PRODUCT } \\
\text { SIZE }\end{array}$ \\
\hline MEc A1 & 5' GTAGAAATGACTGAACGTCCGATAA & \\
\hline MEc A2 & 5'CCAATTCCACATTGTTTCGGTCTAA & 10 BP \\
\hline
\end{tabular}

\section{Results}

The prospective study was conducted over a period of 18 months in the Department of Microbiology, Meenakshi Medical College and Research Institute, Ethanur, Kanchipuram between March -2014 to August 2015. Out of 1240 cases operated in the Obstetrics and Gynaecology Department, 62 cases developed symptoms and signs of SSI.

Table 1: Distribution of isolates among ssi $(n=62)$ 
Surgical Site Infection And Incidence Of Mrsa Using Phenotypic And Genotypic Methods....

\begin{tabular}{|l|l|l|}
\hline Isolate & No. Of isolates & Percentage \\
\hline Staphy lococcus aureus & 35 & $56.45 \%$ \\
\hline $\begin{array}{l}\text { Coagulase Negative } \\
\text { Staphylococcus }\end{array}$ & 2 & $3.23 \%$ \\
\hline .Pseudomonas ae ruginosa & 7 & $11.3 \%$ \\
\hline .Klebsiella pne umonia & 5 & $8.07 \%$ \\
\hline .Escherichia coli & 4 & $6.45 \%$ \\
\hline culture negative SSIs & 9 & $14.5 \%$ \\
\hline Total & 62 & $100 \%$ \\
\hline
\end{tabular}

The predominant isolate was Staphylococcus aureus (56.45\%) from the organism isolated from culture positive SSIs.

Table 2: comparision between type of surgery in ssi cases $(n=1240)$

\begin{tabular}{|l|l|l|l|}
\hline TYPE OF SURGERY & Infected & $\begin{array}{l}\text { Not } \\
\text { infected }\end{array}$ & $\begin{array}{l}\text { Total no } \\
\text { of Surgery }\end{array}$ \\
\hline $\begin{array}{l}\text { Total Abdominal } \\
\text { Hysterectomy }\end{array}$ & $20(1.6 \%)$ & $183(14.8 \%)$ & $203(16.4 \%)$ \\
$\begin{array}{l}\text { Lower Segment } \\
\text { Caesarean Section }\end{array}$ & $39(3.1 \%)$ & $528(42.6 \%)$ & $567(45.7 \%)$ \\
\hline Sterilization & $2(0.2 \%)$ & $264(21.3 \%)$ & $266(21.5 \%)$ \\
\hline Salphingo-oophrectomy & $1(0.1 \%)$ & $167(13.4 \%)$ & $168(13.5 \%)$ \\
\hline Oophrectomy & $0(0 \%)$ & $3(0.2 \%)$ & $3(0.2 \%)$ \\
\hline Ovarian cystectomy & $0(0 \%)$ & $16(1.3 \%)$ & $16(1.3 \%)$ \\
\hline Salphingectomy & $0(0 \%)$ & $17(1.4 \%)$ & $17(1.4 \%)$ \\
\hline Total & $62(5 \%)$ & $1178(95 \%)$ & $1240(100 \%)$ \\
\hline
\end{tabular}

Table 3: comparision between nature of surgery in ssi cases $(n=1240)$

\begin{tabular}{|l|l|l|l|}
\hline Nature of surgery & Infected & Not infected & Total \\
\hline Elective & $40(3.5 \%)$ & $1088(96.5 \%)$ & $1128(100 \%)$ \\
\hline Emergency & $22(19.6 \%)$ & $90(80.4 \%)$ & $112(100 \%)$ \\
\hline
\end{tabular}

Table 3: comparision between nature of surgery in ssi cases $(n=1240)$

\begin{tabular}{|c|c|c|c|c|c|c|c|c|c|c|c|}
\hline Antibiotic & $\mathrm{CONC}$ & RATI & RAN & (1 & & & & & & & \\
\hline $\begin{array}{l}\text { Cefoxitin } \\
(\mathrm{N}=7)\end{array}$ & 2048 & 1024 & 512 & 25 & 128 & 64 & 32 & 16 & 8 & 4 & 2 \\
\hline Mic & $E$ & 2 & 3 & 1 & 1 & - & - & - & - & - & 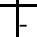 \\
\hline $\mathrm{Mbc}$ & 4 & 3 & - & 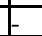 & - & 1 & - & - & - & - & 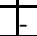 \\
\hline
\end{tabular}

$\leq 4 \mu \mathrm{g} / \mathrm{ml}=\operatorname{mec}$ A negative

A total of 7 cefoxitin resistant isolates were taken for MIC which showed resistance in the range 0 f $>4 \mu \mathrm{g} / \mathrm{ml}$.

Table 5: Cel picture shows positive for mec A(310bp)

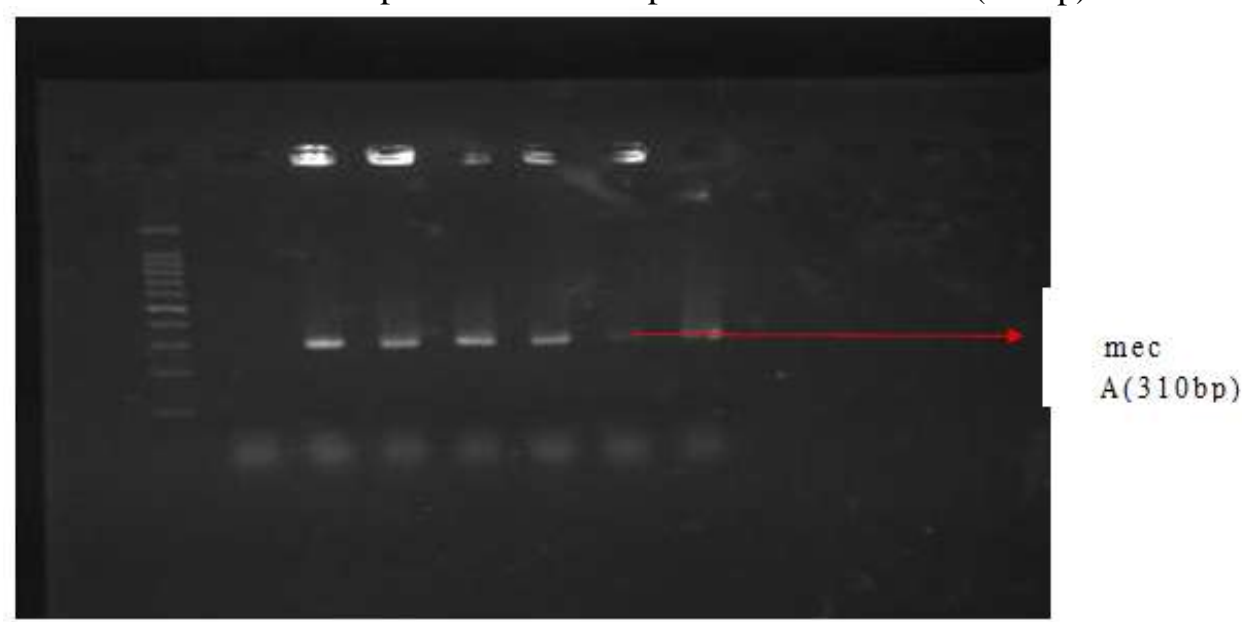

Table 6: comparison of three phenotypic methods with genotypic method of detection of mrss (n $=35$ ). 
Surgical Site Infection And Incidence Of Mrsa Using Phenotypic And Genotypic Methods....

\begin{tabular}{|l|l|l|l|}
\hline Test method & $\begin{array}{l}\text { Detected } \\
\text { As mrsa }\end{array}$ & $\begin{array}{l}\text { Detected } \\
\text { As mssa }\end{array}$ & Total \\
\hline $\begin{array}{l}\text { Oxacillin disc } \\
\text { Diffusion }(1 \mu \mathrm{g})\end{array}$ & $6(17.1 \%)$ & $29(82.9 \%)$ & $35(100 \%)$ \\
\hline $\begin{array}{l}\text { Oxacillin screen } \\
\text { Cefoxitin disc } \\
\text { Diffusion }(30 \mu \mathrm{g})\end{array}$ & $6(17.1 \%)$ & $29(82.9 \%)$ & $35(100 \%)$ \\
\hline Pcr for mec A gene & $7(20 \%)$ & $28(80 \%)$ & $35(100 \%)$ \\
\hline
\end{tabular}

\section{Discussion}

Post operative surgical wound infection remains a major cause of death in surgical patients. It is reported approximately in 500,000 patients undergoing surgery per year out of 27 million estimated surgical procedures per year. During the mid 70's the hospital stay was doubled and cost of hospitalization was also increased when postoperative infections developed after six common operations. But, today most surgical procedures are done on outpatient basis like laproscopy / minimally invasive surgeries which requires only short duration of postoperative stay. SSIs reported in these patients are being diagnosed and treated as OP cases. SSI is a major source of morbidity and mortality that is becoming a burden to the medical sevices in the developing countries.

The overall incidence of SSI in India varies from 4 to $30 \% .^{(1,3,15,25)}$ In present study $5 \%$ of SSIs were reported from Obstetrics and Gynaecology patients. This was concordant with 3 who has also reported $6.12 \%$ and Varsha shahane et al who has repoted 6\% from Obstetrics and Gynaecology patients. The incidence is slightly lower than Jyoti Sonawane et al who has reported 10\% of SSIs in the patients undergoing surgery in Obstetrics and Gynaecology ward Vidyadhar B. Bangal et al reported that the incidence of surgical site infections was 2.8 percent which was lower than our study. This may be attributed the reason that incidence vary among each hospital, surgeon operating and also varies among each ward present within the hospital.

The higher incidence of SSIs in LSCS can be attributed to factors like increased incidence of emergency surgeries, repeated vaginal examination during trial labour, premature rupture of membranes \& prolonged labour. The lower incidence of SSIs in sterilization and salphingo-oophrectomy can be due to shoter duration of surgery and no contamination from vagina. In present study the incidence of SSIs among patients who underwent emergency surgery was $19.6 \%{ }^{(40)}$ followed by elective surgeries $3.06^{\%(22)}$ respectively which was concordant with higher SSI rate among the emergency case $16.01 \%$ followed by elective cases $3.67 \%$ reported by Amirta et al. Emergency surgeries were usually associated with complications like anaemia, advanced age, comorbidities and diabetes among gynaecological surgeries and prolonged rupture of membranes, previous LSCS and multiparity among obstetric cases.

In our study Staphylococcus aureus showed highest resistance to Ampicillin 21(60\%) followed by Ciprofloxacin 17(48.6\%), Cotrimoxazole 16(45.7\%) and Amoxyclav 14(40\%) which was concordant with Jyoti sonawane et al who has reported highest resistance with penicillin 119(75.32\%) followed by Cotrimoxazole 109(68.99\%) and Ciprofloxacin 102(64.56\%) respectively. The study showed all the Staphylococcus aureus isolates were 100\% sensitive to Vancomycin and 20\% MRSA were isolated from SSIs which is slightly lower than Jyoti Sonawane et al who isolated 27.8\% MRSA in SSIs .

\section{Conclusion}

The present study has given us the knowledge about the SSIs and their incidence in obstetrics and gynaecology department of our hospital, it also emphasized on the fact that the surgical site infections rate were increased in emergency surgeries. The incidence of MRSA can be reduced by screening and treating all the hospital staff and the patient undergoing surgery those who carry the MRSA strains Strict adherence to standardised infection control policies and antibiotic policy will decrease the SSIs due to hospital acquired multidrug resistant microorganisms.

A working knowledge of the prevalent organism, virulence and resistance profile will help the infection control practitioner and surgeon to treat the infection effectively at the earliest and also decreases economic burden due to SSI. It also prevents spread of multidrug resistant strains like MRSA which increases mortality and morbidity in patients undergoing surgery. The patients undergoing surgery and hospital staff should be screened for colonisation with MRSA to prevent SSIs and spread of hospital acquired infections. To prevent the emergence of multidrug resistant bacteria, judicious use of antibiotics to treat the patients today and preservation of newer drugs for future generation should be adopted, whenever possible.

\section{Reference}

[1]. Amrita R. Bhadauria*, Chella Hariharan. Clinical study of post operative wound infections in obstetrics and gynaecological surgeries in a tertiary. 
Surgical Site Infection And Incidence Of Mrsa Using Phenotypic And Genotypic Methods....

[2]. $\quad$ care set up. Int J Reprod Contracept Obstet Gynecol. 2013 Dec;2(4):631638

[3]. Dr Nandita Pal, Dr Rajyasri Guhathakurta (Mukherjee). Surgical site infection in surgery ward at a tertiary care hospital: the infection rate and the bacteriological profile. IOSR Journal of Pharmacy Sep-Oct. 2012;Vol. 2(5):pp.01-05

[4]. Dr. Anand Saxena, Dr. Mahendra Pratap Singh, Dr. Swagata Brahmchari, Dr. Malay Banerjee. Surgical site Infection among postoperative patients of tertiary care centre in Central India - A prospective study. Asian

[5]. Journal of Biomedical and Pharmaceutical Sciences 3(17) 2013, 41-44

[6]. Dr. Pravin Suryawanshi, Dr. A. Q. Khan, Dr. Saiyyad Altaf G, Dr. Amey Patil. Analysis of Organisms Found at Incision Site IntraOperatively and its Implications with Post-Operative infections. International Journal of Scientific and Research Publications, Volume 4, Issue 4, April 2014

[7]. F. Gary Cunningham, Kenneth J, Leveno, Steven L. Bloom, Catherine Y. Spong, Jodi S. Dashe, Barbara L. Hoffman, Brlan M. Casey, Jeanne S. Sheffield. Williams OBSTETRICS 24th Edition. McGraw Hill Education.

[8]. Forbes BA,Sham DF,Weissfeld AS, Editors Bailey Scott's Diagnostic Microbiology. 13th edn.USA:Mosby Inc,2002

[9]. Gamal A. Khairy, Abdelmageed M. Kambal, Abdullah A. Al-Dohayan, Mohammed Y. Al-Shehri, Ahmad M. Zubaidi, Mohammed Y. Al-Naami, Faisal A. AlSaif, Omar A. Al-Obaid, Abdulaziz A. Al-Saif, Omer Y. El

[10]. Farouk and Amal A. Al-Abdulkarim. Surgical Site Infection in a Teaching Hospital: A Prospective Study. Journal of Taibah University Medical Sciences 2011; 6(2): 114-120

[11]. Gayathree Naik, Srinivas R. Deshpande. A Study on Surgical Site Infections Caused by Staphylococcus Aureus with a Special Search for Methicillin-Resistant Isolates. Journal of Clinical and Diagnostic Research. 2011 June, Vol-5(3): 502-508

[12]. Horan TC, Gaynes RP, Martone WJ, et al. Definitations of nosocomial surgical site infections; 1992: a modification of CDC definitions of surgical wound infections. Infection Control Hospital Epidemiology. 13

[13]. (1992) 606-608

[14]. Jyoti Sonawane, Narayan Kamath, Rita Swaminathan, Kaushal Dosani. Bacterial Profile of Surgical Site Infections and Their Antibiograms in a Tertiary Care Hospital in Navi Mumbai. Bombay Hospital Journal2010;

[15]. Vol. 52(3): 358-361

[16]. KB Anand, P Agrawal, S Kumar, K Kapila. Comparison of cefoxitin disc diffusion test, oxacillin screen agar, and PCR for mecA gene for detection of MRSA. Indian Journal of Medical Microbiology 2009; 27(1): 27-9

[17]. Kownhar H, Shanker EM, Vignesh R, Sekar R, Velu V, Rao VA: High rate of isolation of S.aureus from Surgical Site Infections in an Indian Hospital; J Antimicrobial Chemotherapy-Vol 61, Suppl 3 pp 758760:Oct 2008

[18]. Madhusudhan NS and Mareena Thomas. Study of Surgical site infection in clean and clean contaminated surgeries in a tertiary care hospital. International Journal of Biomedical Research 2014;05(08): 490-493

[19]. Mandell, Douglas, and Bennet. PRINCIPLES AND PRACTICE OF INFECTIOUS DISEASES 8th edition. Philadelphia: CHURCHILL LIVINGSTONE ELSEVIER.

[20]. Mangram AJ, et al. Guideline for prevention of surgical site infection, 1999. Centers for Disease Control and Prevention (CDC Hospital Infection Control Practices Advisory Committee. Am J Infect Control. 1999; 27: 7-132 16. Monica cheesebrough. Microbiological tests. In: District Laboratory Practice in Tropical Countries. Part 2. Low price edition. Cambridge University Press. UK 2000;

[21]. Priti Goyal, Meenakshi Kashyap, Sushila Khuteta, Shrigopal Goyal, Suchitra Narayan, R P Khuteta. Study of surgical site infection in obstetrics and gynecology at tertiary care centre in India. Int J Res Med. 2013; 2(3);73-77

[22]. Ramesh, Ms. R. Dharini. Surgical site infections in a teaching Hospital. Clinio Microbiological and Epidemiological profile. Int J Biol Med Res. 2012; 3(3): 2050-2053

[23]. Ravinder Reddy, Jhansi Vani, Prashant S. Gade, Swapnil V. Kurkure. Trends in surgical site infections in general surgery at a tertiary hospital. J Med Allied Sci 2012; 2 (1): 19-22

[24]. Saraswathi, R., Velayutharaj, A., Shailesh Kumar and Umadevi, S. Prevalence of pathogenic microbes in post operative wound infections in various surgical specialities. International Journal of Development Research August, 2014; Vol. 4(8): pp. 1783-1786

[25]. Shrestha S, Shrestha R, Shrestha B, Dongol A. Incidence and Risk Factors of Surgical Site Infection Following Cesarean Section at Dhulikhel Hospital. Kathmandu Univ Med J 2014;46(2):113-6

[26]. Syeda Sitwat Fathima, Saima Gilani, Jamila Naib, Zakria Sharafat, Tayyaba Mazhar, Parveen Naveed. Antimicrobial sensitivity patterns of bacterial isolates from Surgical site infections in Obstetrics and Gynaecology. J. Med. Sci. October 2013;Vol. 21(4): 201-205

[27]. Varsha Shahane, Saikat Bhawal, Upendra Lele. Surgical site infections: A one year prospective study in a tertiary care center International Journal of Health Sciences, Qassim University Jan. 2012; Vol. 6(1): 7984

[28]. Vidyadhar B. Bangal, Sai K Borawake, Kunaal K. Shinde and Satyajit P. Gavhane. Study of Surgical Site infections following gynaecological surgery at tertiary care teaching hospital in Rural India. IJBR (2014);Vol. 05 (02):113-116

[29]. WHO guidelines for safe surgery, 2009. Safe surgery saves lives. http://www.who.int/patients safety/en/ .

[30]. Winn W, Allen S, Janda W, Koneman E, Procop G, Schreckenberger P, Woods G. Koneman's Color Atlas and Text Book of Diagnostic Microbiology 6th edition. Philadelphia: Lippincott Williams and Wilkins 